\title{
«LAS MAYORES FIESTAS QUE EN ESPAÑA SE VIERON»: EL CONDE DE HARO \\ EN BRIVIESCA (1440)
}

\section{"THE BIGGEST PARTIES EVER SEEN IN SPAIN": THE COUNT OF HARO IN BRIVIESCA (1440)}

JosÉ MANUEL NIETO SORIA

Universidad Complutense de Madrid ${ }^{1}$

http://orcid.org/0000-0001-8746-9685

RESUMEN: En julio de 1440, la comitiva que acompaña a la princesa Blanca de Navarra para su boda con el príncipe Enrique de Castilla llega a la villa de Briviesca, perteneciente al conde de Haro y que en aquel momento es el nuevo hombre fuerte en la corte castellana que preside la comitiva y se ocupará de la recepción en dicha villa. Con este motivo, tal como describe la crónica de Juan II, se realizarán durante cuatro días unas fiestas de una espectacularidad y singularidad tan extraordinaria que el cronista habrá de aludir a ellas como «las mayores fiestas que en España se vieron». En este artículo se aborda el estudio de estas fiestas en el marco de su contexto histórico.

Palabras clave: Castilla, monarquía, nobleza, ceremonias, fiestas.

1. Este trabajo forma parte del Proyecto HAR2016-76174-P Proyecto I+D del Programa Estatal de Fomento de la Investigación Científica y Técnica de Excelencia. Subprograma Estatal de Generación de Conocimiento de la Secretaría de Estado de Investigación, Desarrollo e Innovación «Expresiones de la cultura política peninsular en las relaciones de conflicto (Corona de Castilla, 1230-1504)». 
ABSTRACT: In July 1440, the entourage that accompanied the Princess Blanca of Navarre for her wedding to Prince Henry of Castile arrived at the town of Briviesca, which belonged to the Count of Haro. At that time, he was the new strongman at the Castilian court and the one who was going to preside over the entourage and would be in charge of the reception in that town. On this occasion, as described in the chronicle of John II, a spectacular and unique festival will be held for four days, so extraordinary that the chronicler will refer to it as «the biggest festivities ever seen in Spain». In this article, we will study these festivities in their historical context.

Key words: Castile, monarchy, nobility, ceremonies, festivities.

En la lectura de la Crónica de Juan II de Fernán Pérez de Guzmán podemos entresacar el siguiente fragmento: «é de allí se partieron todos para Briviesca, donde el Conde de Haro tenia aparejado las mayores fiestas de mas nueva y estraña manera que en nuestros tiempos en España se vieron». ${ }^{2}$ Con estas expresiones tan admirativas e infrecuentes en el relato cronístico de quien fue coetáneo de los acontecimientos se está haciendo referencia a las espectaculares fiestas organizadas por el Conde de Haro, don Pedro Fernández de Velasco, en Briviesca, en julio de 1440, organizadas con motivo de la llegada a esta villa de la comitiva que acompañaba a Blanca de Navarra para contraer matrimonio con el príncipe don Enrique de Castilla. El que la alusión a aquellos hechos se produzca en tales términos no puede pasar indiferente al historiador. De las circunstancias y desarrollo de estas fiestas singulares nos ocuparemos en las siguientes páginas.

\section{EL ORGANIZADOR DE LAS FIESTAS}

Don Pedro Fernández de Velasco, primer conde de Haro es, sin duda, uno de los personajes de mayor peso político durante los reinados de Juan II y Enrique IV de Castilla, a lo que se une una personalidad de variados e interesantes perfiles. El linaje de los Velasco, cuyos orígenes se remontaban a comienzos del siglo XIII, ${ }^{3}$ siendo su fundador Sancho Díaz de Velasco, había alcanzado la ricahombría en estrecha asociación con la entronización y

2. Fernán Pérez de Guzmán: «Crónica de Juan II», Crónicas de los Reyes de Castilla, II, Madrid: Atlas, 1953, p. 565.

3. Trayectoria de conjunto del linaje en Gonzalo Martínez DíEz: «El linaje de los Velasco», Boletín de la Institución Fernán González, 238, 2009, pp. 107-154. 
consolidación de la dinastía Trastámara. ${ }^{4}$ Precisamente fruto de esta vinculación del linaje de los Velasco con la causa trastamarista fue el que recibiera la villa de Briviesca por donación de Enrique de Trastámara estando reunidas las cortes de Burgos de 1367, en plena contienda civil en la lucha por el trono. ${ }^{5}$

El primer conde de Haro, ${ }^{6}$ nacido el 4 de julio de 1401, murió en Medina de Pomar el 25 de febrero de 1470. ${ }^{7}$ Primogénito del matrimonio entre Juan Fernández de Velasco y María Solier, heredó uno de los patrimonios más importantes de Castilla, ${ }^{8}$ al ser su padre el cabeza del linaje de los Velasco, poseedor de extensos señoríos sobre todo en Palencia y en las Merindades de Castilla, a la vez que de su madre había heredado el señorío de Villalpando. ${ }^{9}$

Fernando del Pulgar le dedica extensa atención en sus Claros varones, ofreciendo una visión bastante positiva del personaje, coincidiendo en esta valoración favorable con otros autores como Diego Enríquez del Castillo y Diego de Valera, mientras que Alonso de Palencia contrapone la codicia del personaje con su búsqueda de la paz en tiempos turbulentos. ${ }^{10}$ Así, cabe destacar cómo Pulgar lo presenta como alguien que

Fablaua con buena gracia (...) temeroso de Dios, e omme de verdad, e inclinado a iusticia (...) fue grand zelador de la iusticia, que no se puede dezir otro en sus tiempos que con tan grand estudio la mirase, ni con mejor diligencia e moderación la cumpliese e executase. ${ }^{11}$

Su incorporación a la vida política efectiva se produce en 1418 , casi en coincidencia con el comienzo de la mayoría de edad de Juan II. De su proximidad al rey en el inicio del reinado ya da testimonio la obtención de distintos privilegios en los primeros días de 1420, en los que se le confirmaba su señorío sobre Medina de Pomar $^{12}$ y la merced real de la villa de Briviesca, ${ }^{13}$

4. Esther González Crespo: Elevación de un linaje nobiliario castellano en la Baja Edad Media: los Velasco, Madrid: Universidad Complutense de Madrid, 1981.

5. Diego Arsuaga Laborde: Pedro Fernández Velasco, primer conde de Haro: un estudio de la figura de un ricohombre en la Castilla del cuatrocientos, Madrid: Universidad Nacional de Educación a Distancia, 2015, p. 64. Puede consultarse en: http://e-spacio.uned.es/fez/view/tesisuned:GeoHis-Darsuaga.

6. Un bosquejo biográfico detallado en GonzÁlez Crespo, pp. 284-301. Más recientemente, el personaje ha sido objeto monográfico de una tesis doctoral ya citada en la nota anterior: ARSUAGA LABORDE.

7. González Crespo, p. 284.

8. Detallado análisis de toda la base patrimonial del conde de Haro y de cómo se llevó a cabo su proceso de formación en: Arsuaga Laborde, pp. 36-83.

9. Antonio Moreno Ollero: «El señorío de Villalpando: de Arnao de Solier al Conde de Haro», Primer Congreso de Historia de Zamora, III, Zamora: Diputación Provincial de Zamora, 1991, pp. 397-410.

10. Arsuaga Laborde, pp. 131-144.

11. Fernando del Pulgar: Claros varones de Castilla, edición de J. Domínguez Bordona, Madrid: Espasa Calpe, 1969, p. 29.

12. Archivo Histórico Nacional: Sección Nobleza, Haro, carp. 327, doc. 13 (15-I-1420).

13. Archivo Histórico Nacional: Sección Nobleza, Haro, carp. 327, doc. 17 (15-I-1420). 
estando ya presente en alguno de los acontecimientos políticos más significativos del comienzo del reinado. Este es el caso del auto de Ávila de 1420, en el que, bajo una apariencia de Cortes, se trató de legalizar el golpe de Tordesillas de ese mismo año y los efectos políticos resultantes que supusieron, sobre todo, que el infante de Aragón don Enrique asumía, de hecho, el control del poder regio. ${ }^{14}$

El título de conde de Haro, junto con las villas de Haro y Belorado, serían obtenidos como consecuencia del reparto de bienes y mercedes que se lleva a cabo por Juan II de Castilla a costa del patrimonio castellano del rey de Navarra, ${ }^{15}$ otorgamiento que se produce el 8 de diciembre de 1429, estando reunidas las cortes en Medina del Campo, ${ }^{16}$ no tomando posesión de ellas hasta el año siguiente.

A pesar de su continuada presencia en la vida política del reino y su destacado protagonismo en él, lo que se hace bien patente en el disfrute de los oficios de camarero mayor del rey y merino mayor de Castilla la Vieja, ${ }^{17}$ toman especial relieve dos rasgos que le dan una dimensión singular entre el conjunto de los grandes señores de la nobleza castellana de su tiempo: sus inquietudes culturales y su piedad religiosa.

Por lo que se refiere al primero de estos dos rasgos, sus inquietudes culturales, de ello ya da claro indicio Pulgar cuando afirma que «aprendió letras latinas, y dáuase al estudio de corónicas, e saber fechos pasados. Plazíale asimismo la comunicación de personas religiosas e de ommes sabios, con los cuales comunicaua sus cosas». ${ }^{18}$ Buena expresión de estas inquietudes intelectuales se encuentra en su biblioteca, que puede considerarse como una de las de mayor importancia de las que ha quedado testimonio de aquella época en Castilla gracias a los inventarios conservados. ${ }^{19}$

Por lo que se refiere a sus inquietudes religiosas, estas no se limitaron a las meras actividades de fundación y patronazgo, como sucede entre los nobles principales de su tiempo, aun siendo las mismas muy importantes. Precisamente, dentro de ese tipo de iniciativas se pueden destacar las mer-

14. José Manuel Nieto Soria: «El auto de Ávila de 1420», en María IsABel del VAl Valdivieso y Pascual Martínez Sopena (dirs.): Castilla y el mundo feudal. Homenaje al profesor Julio Valdeón, II, Valladolid: Junta de Castilla y León, 2009, pp. 679-690. Sobre la presencia en él de Pedro Fernández de Velasco ver Ibidem, p. 685.

15. PÉrez de GuZMán, p. 479.

16. Arsuaga Laborde, p. 155.

17. Arsuaga Laborde, pp. 109-112.

18. Pulgar, p. 33.

19. Antonio Paz y Meliá: «Biblioteca fundada por el Conde de Haro en 1455», Revista de Archivos, Bibliotecas y Museos, 1897, pp. 18-24, 60-66, 156-163, 255-262, 452-462; 4, 1900, pp. 535-541, 662-667; 6, 1902, pp. 198-206, 372-382; 7, 1902, pp. 51-55; 19, 1908, pp. 124-136; 20, 1909, pp. 277-289 y JEREMY N. H. LAWRANCE: «Nueva luz sobre la biblioteca del conde de Haro: inventario de 1455», El Crotalón, 1984, pp. 1073-1111. 
cedes realizadas a favor de los franciscanos de Briviesca, ${ }^{20}$ la fundación de un convento de clarisas en Medina de Pomar, junto con un hospital para pobres, ${ }^{21} \mathrm{o}$ las arcas de limosna para pobres que funda en Medina de Pomar, Briviesca, Villadiego, Herrera de Pisuerga, Salas de los Infantes, Belorado, Arnedo y Grisaleña, ${ }^{22}$ asegurando generosa dotación para esta notable iniciativa de asistencia social. ${ }^{23}$

Esta inclinación hacia la piedad religiosa tomará especial presencia al final de sus días pues, más allá de estas iniciativas fundacionales y tras dejar todos los asuntos en manos de su hijo mayor, los diez últimos años de su vida los pasaría completamente retirado de la vida pública en su fundación de clarisas de Medina de Pomar. A este periodo final de su existencia alude Pulgar en los siguientes términos:

E como quier que fue requerido algunas vezes por el rey, e por otros grandes señores sus parientes, que saliese de aquel retraimiento para entender en las disensiones que en aquellos tiempos acaecieron en el reino, no quiso mudar su propósito, antes acordó tomar en su casa compañía de ommes religiosos de buena e onesta vida, e fizo grande y estrecha inquisición sobre las cosas de su conciencia desde el día que fue de hedad para pecar, e cometióles que alimpiasen su ánima, así en la penitencia de su persona como en la restitución que deuía fazer de sus bienes: et todos los que en aquellos tiempos vinieron a le demandar cualquier cargo, así de seruicios que le ouiesen fecho, como de otra cualquier calidad a que de iusticia fuese obligado, fueron oídos e satisfechos. ${ }^{24}$

\section{LAS CIRCUNSTANCIAS POLÍTICAS INMEDIATAS}

Bien se puede afirmar que desde la primavera de 1439 y hasta que tenga lugar la boda el príncipe don Enrique, en septiembre de 1440, el conde de Haro ocupa una posición decisiva en la mayor parte de las iniciativas políticas más relevantes de la corte castellana, por lo que su papel como organizador de las fiestas de Briviesca a las que aludiremos puede considerarse como una expresión simbólica más de tal circunstancia, así como una oportunidad de afirmación festiva y ceremonial de este liderazgo político.

20. Archivo Histórico Nacional: Sección Nobleza, Frías, caja 292, doc. 22 (23-VII-1441).

21. Pulgar, 34. doc. 42

22. González Crespo, p 291; Archivo Histórico Nacional: Sección Nobleza, Frías, caja 258,

23. José López Yepes y Félix SAgredo Fernández: «Las Arcas de Limosna del Conde de Haro y las Instituciones de préstamo benéfico (siglos XV-XVI)», en A pobreza e a assisténcia aos pobres na península ibérica durante a Idade Média, II, Lisboa: Instituto de Alta Cultura. Centro de Estudios Históricos Anexo à Faculdade de Letras da Universidade de Lisboa, 1975, pp. 547-574

24. Pulgar, p. 34. 
Fue el conde de Haro el hombre, sin duda, decisivo en las complejas negociaciones conocidas como el Seguro de Tordesillas ${ }^{25}$ con el que, un año antes, se había definido el nuevo marco de relaciones en torno al rey con el consiguiente, aunque transitorio, desplazamiento de su gran privado, Álvaro de Luna. Así, Juan II dio los poderes al conde de Haro que este precisaba para que, con toda la legitimidad de actuar en nombre del rey, pudiera tomar las previsiones necesarias para que fuera posible aquel encuentro. ${ }^{26} \mathrm{Con}$ aquel pacto se querían redefinir por completo las relaciones políticas entre los principales personajes del reino, en especial, en lo que afectaban a las que mantenía el monarca castellano con los infantes de Aragón y con su privado don Álvaro de Luna. Así, sería don Pedro Fernández de Velasco el organizador de aquel acontecimiento, actuando como mediador a múltiples bandas, garantizando la seguridad de los asistentes, desplegando todo un protocolo que evitase las suspicacias entre los negociadores y siendo el receptor principal de los múltiples juramentos que se siguieron en el transcurso de aquellas jornadas y que daban garantía de cumplimiento de lo pactado.

Tras las negociaciones de Tordesillas, en Castronuño se concertarían nuevas entrevistas de las que actuaría como garante de su pacífico desarrollo el conde de Haro quien, por aquellos días, ya en septiembre de 1439,27 se multiplicaría en la actividad negociadora entre las diversas partes hasta llegar el 22 de octubre a la firma del acuerdo por el que se decidía la salida de la corte de don Álvaro de Luna, con lo que parecía abrirse un nuevo tiempo político. ${ }^{28}$ En este nuevo contexto, la posición central del conde se consolidaba dentro del grupo político más influyente, ${ }^{29}$ tal como que se puso aún más de manifiesto, entre marzo y abril de $1440{ }^{30}$ en el compromiso jurado por el monarca en Bonilla de la Sierra por el que confiaba todos sus asuntos a las personas de los condes de Haro y de Benavente. ${ }^{31}$

25. González Crespo, 303-314, Nancy F. Marino: El Seguro de Tordesillas del conde de Haro don Pedro Fernández de Velasco, Valladolid: Secretariado de Publicaciones de la Universidad de Valladolid, 1992; ANa IsABel CarRasco MANChado: «Léxico político en el Seguro de Tordesillas: conflicto, pactos y autoridad», en François Foronda y Ana Isabel Carrasco Manchado (dirs.): Du contrat d'alliance au contrat politique. Cultures et sociétés politiques dans la péninsule Ibérique à la fin du Moyen Age, Toulouse: Université de Toulouse, 2007, pp. 85-137; María del Pilar Rábade Obradó: «Confederaciones, seguros y pleitos homenajes: el contexto documental del Seguro de Tordesillas», en F. Foronda, y A. I. Carrasco Manchado, (dirs.): Du contrat d'alliance, pp. 65-84; Fernando Gómez Redondo: Historia de la prosa medieval castellana, III, Madrid: Cátedra, 2002, pp. 2.397-2.409 y, del mismo autor, «Elocución y diplomacia: rivalidades culturales en Tordesillas», en F. Foronda, A.I. Carrasco Manchado, (dirs.): Du contrat d'alliance, pp. 49-64.

26. Archivo Histórico Nacional: Sección Nobleza, Frías, carpeta. 283, doc. 1 (10-VI-1439).

27. Extensa referencia a la documentación dada en Castronuño en FrANCISCO DE PAULA CAÑAs GÁLVEZ: Itinerario de la corte de Juan II (1418-1454), Madrid: Dykinson, 2007, pp. 334-335.

28. GonzÁlez Crespo, pp. 314-315.

29. Archivo Histórico Nacional: Sección Nobleza, Osuna, caja 1860, doc. 3.

30. Cañas Gálvez, pp. 340-341.

31. PÉrez de Guzmán, p. 563-564. 
En consecuencia, el protagonismo del conde de Haro como organizador del itinerario, escenografía y actividad festiva del séquito que habría de traer a la princesa navarra para su boda con el príncipe heredero de Castilla era una expresión más del nuevo papel que este personaje había alcanzado en la corte castellana, siendo una oportunidad que no podía dejar pasar para confirmar sus merecimientos para el ejercicio de este liderazgo.

\section{UN ITINERARIO FESTIVO}

El 20 de septiembre de 1436, en Toledo, los embajadores de Navarra y Aragón habían alcanzado un importante acuerdo con el monarca castellano por el que se comprometían a alcanzar paces perpetuas entre los tres reinos, estableciéndose como garantía de mantenimiento de esta nueva relación entre ellos el que el príncipe don Enrique de Castilla casase con la hija de los reyes de Navarra, la princesa Blanca, redactándose el correspondiente contrato matrimonial. ${ }^{32}$ En consecuencia, la importancia política del pacto matrimonial resultaba evidente para afirmar la colaboración dinástica entre los tres tronos con presencia de un Trastámara. Así se efectuó el desposorio por palabras, dada la corta edad de los príncipes, quedando pendiente, según la Crónica del Halconero, la consecución de la dispensa papal, dados los vínculos de consanguinidad existentes entre los contrayentes. ${ }^{33}$ Sin embargo, en este punto, la crónica está mal informada, puesto que la dispensa pontificia de Eugenio IV se había emitido en Bolonia el 26 de mayo de ese mismo año, con lo cual el acuerdo matrimonial se llevó a cabo con todas las garantías de legalidad propias del caso. ${ }^{34}$

Fue en ese nuevo tiempo político que se había abierto de aproximación entre los reyes de Castilla, Navarra y Aragón, cuyo rasgo más destacado para Castilla, además de esta relación entre los tres monarcas, era la expulsión de don Álvaro de Luna de la corte, en la que pasaba a ocupar una posición de gran influencia el conde de Haro, cuando se acordó llevar definitivamente a efecto el matrimonio concertado cuatro años antes, una vez que el príncipe había alcanzado los quince años. ${ }^{35}$ De estas nuevas circunstancias políticas, en las que se contextualizaba la urgencia del matrimonio como instrumento al servicio del mantenimiento de una paz que se antojaba quebradiza, formó parte la firma de un pacto en el que participaron la reina María de Castilla,

32. Una copia se conserva en ArChivo general De SimanCas: Patronato Real, leg. 12, doc. 18. Fue publicado y comentado en TARSICIO DE AzCONA: «Algunos documentos esenciales sobre Blanca de Navarra, esposa de Enrique IV de Castilla», Príncipe e Viana, 78, 2017, pp. 15-35.

33. Crónica del Halconero, edición de J. M. Carriazo, Madrid, 1946, p. 234.

34. Referencia del documento de dispensa conservado en los registros vaticanos en AzCONA, p. 18.

35. Crónica del Halconero, pp. 343-344. 
el rey Juan de Navarra, el infante don Enrique de Aragón, el almirante de Castilla don Fadrique, el conde de Benavente don Rodrigo Alfonso Pimentel, el conde de Ledesma don Pedro de Zúñiga, el adelantado mayor de León don Pedro Manrique, don Iñigo López de Mendoza y el conde de Haro. ${ }^{36}$

A fin de traer a doña Blanca de Navarra a Castilla, Juan II de Castilla designó una embajada encabezada por el Conde de Haro, y también integrada por Alfonso de Velasco, protonotario apostólico, ${ }^{37}$ Iñigo López de Mendoza ${ }^{38}$ y el obispo de Burgos don Alonso de Cartagena, ${ }^{39}$ oidor y refrendario del rey. En el mismo documento en el que Juan II designaba esta embajada, y que fue dado en Valladolid el 7 de julio de 1440, se dirigía el rey a todos los concejos, ciudades, villas y lugares del reino para que le fueran hechos a la comitiva en la que había de venir la princesa navarra «rrecebimiento e solepnidad e seruiçio que a sus personas e estados pertenesçe». ${ }^{40}$ Mientras la embajada ponía rumbo a Navarra, la corte permanecería en Valladolid, donde estaba prevista la celebración de las nupcias. ${ }^{41}$

Los distintos textos cronísticos que se pueden manejar para conocer los movimientos de la comitiva resultan completamente inútiles a la hora de establecer fechas precisas, si bien cabe pensar que el viaje debió desarrollarse en fines del mes de julio y comienzos de agosto.

Los enviados de Juan II recibieron a la reina Blanca de Navarra y a su hija en Logroño, hasta donde las acompañó el príncipe Carlos de Viana, habiendo recibido cartas de Juan II en las que se establecía esta ciudad de Logroño como lugar de encuentro. A partir de ahí, madre e hija continuarían el camino en compañía del cortejo comandado por el conde de Haro, siendo este el que tomó las decisiones tocantes al itinerario y los ritmos a seguir. Así cabe deducirlo a partir de la descripción de conjunto que hace del viaje Alfonso de Palencia, una vez que se produjo el encuentro en Logroño:

El obispo saludó ceremoniosamente a la reina en nombre de todos, y luego expuso el objeto de su embajada en elocuente discurso público. A los pocos días la reina y su hija se pusieron en camino con gran pompa, acompañadas por los

36. Archivo Histórico Nacional: Sección Nobleza, Osuna, caja 1860, doc. 3 (30-I-1440).

37. De este protonotario apostólico el cronista Alonso de Palencia apostilla que «abandonó el hábito eclesiástico para casarse con la noble sevillana Isabel de Cuadros, de quien andaba perdidamente enamorado». Alfonso de Palencia: Gesta Hispaniensia ex annalibus suorum dierum collecta, edición de B. Tate y J. Lawrance, Madrid: Real Academia de la Historia, 1998, p. 4.

38. Muy activo en la política castellana de aquellos años, obtendría el título de marqués de Santillana tras la batalla de Olmedo en 1445: VArios Autores, El marqués de Santillana, 1398-1458. Los albores de la España moderna, 4 vols., Hondarribia: Editorial Nerea, 2002.

39. Una aproximación de conjunto a este personaje en LuIs Fernández Gallardo: Alonso de Cartagena. Una biografía política en la Castilla del siglo XV, Junta de Castilla y León, Valladolid: Junta de Castilla y León, 2002.

40. Archivo Histórico Nacional: Sección Nobleza, Frías, caja 118, doc. 1.

41. Cañas Gálvez, pp. 342-345. 
embajadores y un séquito numeroso y brillante. La marcha fue bastante lenta, porque Pedro Fernández de Velasco se desvió hacia las villas de su condado, donde desplegó gran ingenio en la traza y celebración de espectáculos costosos, y también porque la reina, impedida por la obesidad, caminaba despacio y se detenía mucho tiempo en las villas que la festejaban. ${ }^{42}$

Junto a la falta de señalamiento de fechas concretas que permitan situar cronológicamente el desarrollo del viaje, tampoco se dan indicaciones precisas de duración de cada una de las escalas, por lo que todo se limita a su ubicación entre algunos días después del 7 de julio y su llegada a Dueñas el 3 de septiembre. ${ }^{43}$

Entre ambas fechas, el itinerario seguido pasó por Belorado, villa del conde de Haro; Briviesca, donde las celebraciones durarían cuatro días, realizándose en su mayor parte en las fincas inmediatas al palacio que el conde tenía en esta villa, ${ }^{44}$ llegando seguidamente a Burgos, «donde fue hecho muy notable recebimiento», encontrándose seguidamente con el príncipe don Enrique en Dueñas el 3 de septiembre. ${ }^{45}$

\section{LOS CUATRO DÍAS DE FIESTA Y ESPECTÁCULOS EN BRIVIESCA}

Briviesca era una de las posesiones principales del conde Haro. Las grandes casas nobles castellanas, como en este caso los Velasco, tenían espacios urbanos de exhibición de su poder simbólico en donde buena parte de su arquitectura más relevante estaba concebida para potenciar un mensaje inequívoco de preeminencia del linaje al que estaba asociado el señorío del lugar. En el caso de los Velasco, en la primera mitad del siglo XV, este mensaje simbólico de preeminencia nobiliaria se hacía especialmente potente en el caso de Medina de Pomar y de Briviesca, ${ }^{46}$ tal como se reflejaba en el mecenazgo artístico que los Velasco habían aplicado a ambas villas. ${ }^{47}$

Tal como se verá en el desarrollo de las fiestas celebradas, buena parte de estas requirieron de despliegues escenográficos que requerían grandes

42. Palencia, p. 4.

43. Esta fecha del 3 de septiembre la proporciona Crónica del Halconero, p. 343.

44. Una aproximación a las características urbanísticas de Briviesca en esta época en: ANA ISABEL ORtega Martínez y José Luis Ibarra Álvarez: «La villa de Briviesca en la baja Edad Media: datos y reflexiones para su estudio», Boletín de la Institución Fernán González , 217, 1998, p. 321-352.

45. Pérez de Guzmán, p. 566.

46. Begoña Alonso Ruiz: «La nobleza en la ciudad: Arquitectura y magnificencia a finales de la Edad Media», Studia Historica. Historia Moderna, 34, 2012, pp. 226-227.

47. Sobre las iniciativas arquitectónicas de los Velasco: Elena Paulino Montero: El patrocinio arquitectónico de los Velasco (1313-1512): construcción y un contexto de un linaje en la Corona de Castilla, Madrid, Universidad Complutense de Madrid, 2015. 
espacios abiertos en el entorno de la villa, algunos de los cuales fueron incluso objeto de transformación a fin de servir al objetivo celebratorio que se planteaba en cada caso. Esto fue especialmente factible como consecuencia de la gran disponibilidad de heredades con que contaba el conde de Haro en los alrededores de la población. ${ }^{48}$

Ya en el testamento de Pedro Fernández de Velasco de 1383 se hace referencia al empeño en convertir estas dos poblaciones en expresiones del extraordinario ascenso que el linaje había experimentado con la entronización de los Trastámara a la que habían contribuido de manera relevante. Consecuencia de ello, tal como se expresa en dicho testamento, había sido la rehabilitación de los alcázares de ambas localidades como referentes simbólicos con los que se identificaba el linaje. ${ }^{49}$ El primer conde de Haro siguió los pasos de sus antecesores en lo que se refería a atender adecuadamente a sus principales villas como espacios escenográficos de poder, hasta el extremo de contar con un «mayordomo de mis labores» como principal responsable técnico de sus proyectos artísticos y constructivos. ${ }^{50}$

Briviesca se situaba perfectamente ubicada en la ruta más conveniente desde el reino de Navarra a la ciudad de Burgos, donde se esperaba la llegada de la princesa navarra. Fue aquí donde el conde de Haro debió de emplearse a fondo en la preparación de unas fiestas verdaderamente extraordinarias que conocemos con bastante detalle gracias a la prolijidad con que son descritas por el cronista Fernán Pérez de Guzmán. ${ }^{51}$ Estas fiestas ya habían sido precedidas por el recibimiento dispensado en Belorado, donde el conde había organizado una sala general con respecto a la que se da noticia de la presencia de caballeros extranjeros..$^{52}$

Unas dos leguas antes de que la comitiva llegase a la villa de Briviesca, ya tuvo lugar el primer espectáculo, para lo cual, el conde de Haro había dispuesto la celebración de un gran torneo. En él participaron cien caballeros, cincuenta por cada lado, con «caballos encubertados, y almetes con penachos», unos con distintivos blancos y los otros con distintivos rojos, colores

48. González Crespo, p. 169 y Alfonso Franco Silva: «La formación del patrimonio de la Casa de Velasco (siglo XIII al XV)», Boletín de la Real Academia de la Historia, CCVI, 2009, pp. 231-254.

49. JoAquín YARza LuACES: La nobleza ante el rey. Los grandes linajes castellanos y el arte en el siglo XV, Madrid: Ediciones El Viso y Fundación Iberdrola, 2003, p. 34 y JoAquín YARZA LuACEs: «Imagen del noble en el siglo XV en la Corona de Castilla: Los Velasco anteriores al primer Condestable», en MARISA Costa (coor.), Propaganda y poder, Congresso Peninsular de História da Arte (5 a 8 de Mayo de 1999), Lisboa: Ediciones Colibrí, 2001, pp. 133-134.

50. Paulino Montero, p. 185.

51. En todo lo que sigue con relación a las fiestas de Briviesca seguimos la descripción presentada en PÉREZ de GuZmán, pp. 565-566.

52. Una descripción del desarrollo del viaje en su estancia en Briviesca siguiendo el relato cronístico ya se hizo en: Manuel Martínez añíbarro y rives: «Fernández de Velasco (Pedro), el Buen Conde de Haro» en Intento de un diccionario biográfico y bibliográfico de autores de la provincia de Burgos, Valladolid: Junta de Castilla y León, 1993, pp.177-180. 
que frecuentemente eran utilizados en los torneos organizados en presencia del rey de Castilla como colores que se identificaban con los que simbólicamente se asociaban a Castilla. Tras este entretenimiento, llegaron finalmente a Briviesca.

Llegada la comitiva a Briviesca «fue hecho muy solemne recebimiento». Formó parte de este recibimiento el desfile de los distintos oficios de la ciudad, cada uno con «su pendon é su entremes lo mejor que pudieron, con grandes danzas é muy gran gozo y alegría». Estos datos indican, por tanto, que cada oficio de la ciudad haría alguna forma de pequeña representación teatral, seguramente alusiva al propio oficio. A la vez, también se estaría dando indicio de que tal representación habría sido objeto de una cierta preparación previa con alguna forma de ensayo. Después del desfile de los oficios, harían lo propio los judíos, exhibiendo la Torá, y los moros con el Corán.

$\mathrm{Al}$ cronista no le pasa desapercibido que este tipo de manifestaciones era propio de la primera entrada real que tenía lugar por parte del monarca cuando llegaba por primera vez a una ciudad tras su coronación. ${ }^{53}$ Por ello parece perfectamente pertinente su apreciación de que aquellos actos se llevaron a cabo «en aquella forma que se suele hacer á los Reyes que nuevamente vienen á reynar en parte estraña». Al hacer esta observación se ponía de manifiesto la anomalía y excepcionalidad del procedimiento ceremonial, ya que se estaba aplicando formato de entrada real a una situación a la que no correspondía tal uso al no estar presente el rey de Castilla, único receptor legítimo posible de tal artefacto celebratorio.

Con relación a la presencia de los judíos, que como la de los moros solía ser común en esas entradas reales, seguramente supuso una representación relevante y distinguida, teniendo en cuenta la importancia de la comunidad

53. Algunos análisis sobre entradas reales que permiten comprobar hasta qué punto la llegada a Briviesca se hizo bajo apariencia de entrada real, a pesar de que, institucionalmente, en ausencia del monarca, no procedía aplicar ese formato ceremonial en: ROSANA DE ANDRÉs DíAZ: «Las entradas reales castellanas en los siglos XIV y XV», En la España Medieval, 4, 1984, pp. 47-62; José MANuel Nieto Soria: Las ceremonias de la realeza. Propaganda y legitimación en la Castilla Trastámara, Madrid, Editorial Nerea, 1993, pp. 119 130; Miquel Raufast Chico: «Ceremonia y conflicto: entradas reales en Barcelona en el contexto de la Guerra Civil catalana (1460-1473)», Anuario de estudios medievales, 38, 2008, p. 1037-1085; MiQuel RAUFAST CHICO: «La entrada real de Martín el Joven, rey de Sicilia en Barcelona (1405): solemnidad, economía y conflicto», Acta historica et archaeologica mediaevalia, 27/28, 2006/07, p. 89-120, y RAFAEL NARBONA VizCAínO: «Las entradas reales en Valencia entre la Edad Media y la Edad Moderna. Siglos XIV-XVII», en Memorias de la ciudad. Ceremonias, creencias y costumbres en la historia de Valencia, Valencia: Ayuntamiento de Valencia, 2003, pp. 85-100; Ana Isabel Carrasco Manchado: «La ceremonia de entrada real: ¿un modelo castellano?», en MANUEL GonzÁlez Jiménez e ISABEl MonTEs Romero-CAMACHo, $L a$ Península Ibérica entre el Mediterráneo y A el Atlántico: siglos XIII-XV, Cádiz: Sociedad Española de Estudios Medievales, 2006, pp. 651-656; Diana Pelaz Flores: «El don: Pulso entre el significado del gasto y la simbología del poder en la entrada de la familia real a Burgos en 1441», en Alexandra Beauchamp, Antoni Furió Diego, Germán Gamero Igea y María Narbona Cárceles (eds.), Acoger, abastecer y financiar la corte. Las relaciones entre las cortes ibéricas y las sociedades urbanas a finales de la Edad Media, Valencia: Publicaciones de la Universidad de Valencia, 2019, pp. 347-360 y Gisela CoronAdo SCHwindT: «Las entradas reales en el reino de Castilla hacia el final de la Edad Media; el universo sonoro del poder», Mirabilia. Revista Electrónica de Historia Antigua y Medieval, 29, 2019. 
judaica tanto en Briviesca, así como en los lugares comarcanos bajo el señorío del conde, quien mantuvo intensas relaciones financieras con algunos prestamistas judíos de esta misma villa. ${ }^{54}$ Todo esto se realizó con profuso acompañamiento musical de trompetas, ministriles, tamborinos y atabales, por lo que la sonoridad de tanto instrumento era lo bastante llamativa como para que pareciera «venir una muy gran hueste». Así se llegaría hasta el palacio del conde.

En el palacio ${ }^{55}$ se sirvió el abundantísimo almuerzo, integrado por «tanta diversidad de aves y carnes y pescados y manjares y frutas, que era maravillosa cosa de ver». Dentro de la descripción de esta primera gran comida en el palacio del conde de Haro llama especialmente la atención la cuidada organización del servicio y la perfecta coordinación que parece transmitirse en cuanto a lo que podría considerarse como la etiqueta aplicada a su desarrollo, siendo esta cuestión de la etiqueta en la mesa un asunto que no era ajeno a las inquietudes cortesanas y altonobiliarias en la Castilla de aquel tiempo en las ocasiones solemnes, tal como era el caso. ${ }^{56}$ Así, se nos dice cómo el mobiliario estaba puesto para crear distintos espacios, quedando una mesa exclusivamente reservada a la reina y princesa navarras y al propio conde, mientras que otra, por ejemplo, era ocupada por el obispo de Burgos, junto con otros prelados y clérigos extranjeros. Por su parte, las damas y doncellas que acompañaban a la reina y su hija fueron sentadas de manera que cada una estuviera flanqueada por ambos lados por un caballero. También se señala cómo fueron caballeros, gentileshombres, además de pajes especialmente ataviados para la ocasión, quienes sirvieron las mesas. Con todo ello se estaría buscando ofrecer una imagen de cortesía caballeresca, tal como resultaba característico de las grandes celebraciones nobiliarias que hallaban un momento de expresión particularmente visual e impactante para los participantes con ocasión de sentarse a la mesa. ${ }^{57}$

54. José Antonio García LujÁN: «Una minoría urbana en el estado nobiliario de los Velasco: los judíos a través de las ordenanzas del primer conde de Haro (1431-1476)», en Tolède et l'expansion urbaine en Espagne (1450-1460), Madrid: Casa de Velázquez, 1991, pp. 249-271.

55. La descripción cronística hace claro hincapié en la existencia de un palacio condal en Briviesca del que, sin embargo, salvo un informe de 1531 (PAulino Montero, p. 12) no han quedado más testimonios con relación a sus rasgos arquitectónicos que, en cambio sí son conocidos para otros palacios de los Velasco como el alcázar de Medina de Pomar, el palacio de Casalarreina o el palacio burgalés conocido como la Casa del Cordón. Véase Paulino Montero, pp. 226-279, 283-359 y 540-550.

56. Jeanne Allard: «L'etiquette de table à la cour de Castille au Bas Moyen Age», en Temas medievales, 3, 1993, p. 5-15; JEANne AlLARD: «La naissance de l'etiquette: les règles de vie à la cour de Castille à la fin du Moyen-Age», en Nilda Guglielmi y Adeline Rucquoi (eds.), El Discurso político en la Edad Media, Buenos Aires: Consejo Nacional de Investigaciones Científicas y Técnicas, 1995, pp. 11-28. Desde una perspectiva no específicamente castellana: DANIELA RoMAgNoli: “'Mind your manners': etiquette at the table», en Jean Louis Flandrin y Massimo Montanari (eds.), Food. A culinary history from antiquity to the present, Nueva York: Stein and Day, 1998, pp. 328-338.

57. Antonio M. Contreras Martín: «Comida y cortesía: los rituales alimenticios en la sociedad caballeresca de los siglos XIV y XV», en Actes Ier Col-loqui d'Història de l'Alimentació a la Corona d'Aragó, Lérida: Institut d'Estudis Ilerdencs, 1995, vol. 2, pp. 711-727. 
Un dato especialmente llamativo dentro del palacio del conde es la alusión que se hace a la presencia de una fuente de plata «así artificiosamente hecha» y de la que manaba continuamente vino, dando la impresión de que la fuente fue preparada especialmente para la ocasión. En los tres días que siguieron «siempre hubo danzas de los Caballeros y GentilesHombres en palacio, é momos é toros é juegos de cañas». Sin embargo, las principales celebraciones y alegrías se reservaron para el cuarto día, suponiendo un auténtico alarde de imaginación, a la vez que de fasto.

En un gran prado situado detrás del palacio condal y que se hallaba cercado, se preparó una gran sala, con un graderío muy alto de hasta veinte pisos, cubriéndose todo de césped, lo que daba la apariencia de un montículo cubierto de hierba. Allí se situaron la reina de Navarra y su hija, junto con la condesa de Haro, ubicándose debajo de un dosel de brocado carmesí. En su entorno se colocaron numerosas mesas, donde tomaron asiento los caballeros presentes. En una parte de aquella inmensa sala se instaló una tela de torneo, en donde podían justar hasta veinte caballeros ataviados con arnés de guerra. En otra parte había un estanque, al que se habían llevado especialmente para la fiesta truchas y barbos que, recién pescados y aún vivos, eran servidos en la mesa de las damas. Finalmente, en otra parte de esta inimaginable sala se había simulado una especie de bosque «muy hermoso puesto a mano». Con esta expresión habría que pensar que el cronista se estaría refiriendo a la creación para la ocasión de un bosque ficticio, como lo era ese montículo antes aludido que, en realidad, se levantaba sobre unas gradas. Para mayor realismo, se habían aportado a este bosque de ficción osos, jabalíes y venados, quedando todo ello convenientemente cercado. Su amplitud era la suficiente para que, además de estos animales, pudieran operar en él hasta medio centenar de monteros, con sus correspondientes lebreles y sabuesos. La iluminación, en cuanto que las actividades duraron día y noche, se aseguraba con un gran despliegue de antorchas.

A la vista de esta descripción, no parece exagerada la apreciación del cronista al señalar que todo aquello «pareció cosa muy estraña, en un mesmo tiempo y en una casa poderse hacer tan distintos exercicios», pues, ciertamente, se había creado un espacio en el que, a la vez, se comía, se justaba, se pescaba y se cazaba. Ya entrada la noche, se puso fin a estas actividades para dar paso a las danzas que, gracias a las numerosísimas antorchas, se pudieron realizar como si se dispusiese de la luz del día. Acabada la danza, se serviría aún una colación, mientras que el conde pagaba con dos grandes sacas de monedas a los músicos participantes. Esto, en realidad, fue tan solo el anuncio de los espléndidos regalos que repartió entre los principales asistentes en forma de joyas, rubíes, esmeraldas o diamantes a las damas, «que ninguna quedó sin dél recebir», o de mulas, brocados y sedas a los caballeros, en especial, a los de procedencia extranjera. 
Esta última jornada de las cuatro festivas celebradas en Briviesca acabaría bien avanzada la noche, de tal modo que el cronista señala que, tras el reparto de los regalos, «se dio fin á la fiesta, é todos fueron a dormir eso poco que de la noche quedó», saliendo hacia Burgos a la mañana siguiente, a la hora de tercia.

Llegados a Burgos, no faltarían tampoco los actos de celebración que ahora correrían por parte del concejo y del obispo de Burgos don Alonso de Cartagena, en casa de cuyo hermano, Pedro de Cartagena, se alojaría la reina y princesas navarras, ${ }^{58}$ antes de salir hacia Dueñas, donde se produciría el primer encuentro con el príncipe, el 2 de septiembre y, finalmente, hacia Valladolid, donde se llevaría a efecto la boda el 15 de septiembre.

No cabe dudar de la enorme cuantía de gastos que hubo de suponer esta extraordinaria actividad festiva que se desarrolló a lo largo de aquellos cuatro días en Briviesca como consecuencia de la iniciativa del conde de Haro. Por ello, no habría que descartar la relación entre estas actividades y el préstamo que don Pedro Fernández de Velasco contrajo con los judíos de la aljama de Briviesca aquel mismo año, del que se dio una carta de pago por valor de 10.000 maravedíes el 17 de noviembre de $1440 .{ }^{59}$

Como es bien sabido, el matrimonio del futuro Enrique IV con la princesa Blanca de Navarra terminaría en anulación algo menos de trece años después, ${ }^{60}$ dándose la correspondiente sentencia de divorcio por el administrador apostólico de Segovia, don Luis de Acuña, el 11 de mayo de $1453 .{ }^{61}$

\section{ALGUNAS VALORACIONES INTERPRETATIVAS}

La utilización del viaje ceremonial como un instrumento destinado a inducir y exhibir una actitud de adhesión hacia sus protagonistas, tanto sus organizadores, como, además, en este caso, la princesa y reina de Navarra, fue una práctica ampliamente extendida y constatada en el occidente bajomedieval. ${ }^{62}$ Esa búsqueda de adhesión en el caso que nos ocupa se hacía particularmente urgente si tenemos en cuenta varios hechos.

58. Véase sobre la significación de esta familia en el ambiente burgalés: FRANCISCO CANTERA BURGOS: Alvar García de Santa María, Historia de la judería de Burgos y de sus conversos más egregios, Madrid: Instituto Arias Montano, 1952.

59. Archivo Histórico Nacional: Sección Nobleza, Frías, caja 370, doc. 1.

60. Nicasio Salvador Miguel: «El divorcio del príncipe don Enrique de Castilla y doña Blanca de Navarra (1453)», La literatura en la época de los Reyes Católicos, Madrid: Editorial Iberoamericana, 2008, pp. 249-274.

61. Memorias de don Enrique IV de Castilla, II, Madrid: Real Academia de la Historia, 1835-1913, doc. XXXV, p. 61.

62. Maria Antonietta Visceglia: Riti di corte e simboli della regalità. I regni d'Europa e del mediterraneo dal Medioevo all'età moderna, Roma: Salerno Editrice, 2009, pp. 116-125. 
El primero ha de referirse a cómo estamos ante la recepción de la mujer y la hija del rey de Navarra que, sobre todo durante los diez últimos años, incluso en los meses anteriores a estos acontecimientos, había sido presentado como el enemigo natural de Castilla, y con el que se habían producido recurrentes enfrentamientos armados. Así, por tanto, promover una actitud de adhesión en un contexto de formalización de la paz entre ambos reinos parecía oportuno y urgente, lo que daba sólida justificación, dentro de las prácticas representativas de la época, al desarrollo de un itinerario festivo meticulosamente preparado, en el que cabía la máxima grandilocuencia festiva y ceremonial.

El segundo de estos hechos que nos remiten a las especiales necesidades de promover adhesión debe referirse a los intereses particulares del propio conde de Haro. La paz firmada entre el rey de Castilla y el de Navarra afectaba muy especialmente a los territorios sobre los que ejercía su señorío, próximos a la frontera con Navarra. Era el momento, por tanto, de recibir la adhesión de sus vasallos, teniendo en cuenta que el conde de Haro había sido uno de los forjadores más activos de ese acuerdo de paz, que iba a encontrar su principal expresión simbólica en el matrimonio entre los príncipes Enrique y Blanca. Cabe pensar que los gastos de aquellas celebraciones, con todo su correlato de excesos y de magníficos regalos, supusieran una suma muy elevada. Ya se ha aludido antes a esa carta de pago de 10.000 maravedíes. Pero, por otro lado, no hay que perder de vista que diez años antes, el concejo de Briviesca había hecho un préstamo al conde de otros 30.000 para que éste pudiera atender a las necesidades extraordinarias resultantes de la guerra en la que participaba entonces precisamente contra el rey de Navarra, ${ }^{63}$ que tenía uno de sus principales escenarios en las tierras por las que ahora se desplazaba el cortejo nupcial.

Teniendo en cuenta los datos que se acaban de señalar, considerado el asunto en términos financieros, difícilmente podía considerarse excesivo el desembolso que se realizaba en la línea de evitar un nuevo enfrentamiento armado, si se tienen en cuenta los gastos mucho mayores que podía suponer éste.

El acuerdo de paz entre los reyes de Castilla y Navarra no dejaba de producir ciertos temores entre muchos nobles que, como el conde de Haro, se habían visto beneficiados por el reparto del patrimonio de Juan de Navarra en el reino de Castilla en 1430. Sin embargo, uno de los resultados de las negociaciones que terminaron en aquel acuerdo fue la no alteración de aquella distribución patrimonial. Así, el conde de Haro obtendría el 9 de junio de 1440 la confirmación por Juan II de estos bienes y la definitiva renuncia del rey de Navarra a las villas de Haro y Belorado. Esto, por tanto, sucedía

63. Archivo Histórico Nacional: Sección Nobleza, Frías, caja 386, doc. 124 (17-XI-1430). 
algunas semanas antes precisamente de que se diera comienzo a aquel itinerario festivo. ${ }^{64}$ Este hecho, por sí mismo, bien justificaba la exhibición festiva del éxito del conde, precisamente en el escenario de los territorios directamente afectados, ante los que podía presentarse con todo el reconocimiento real para su señorío sobre ellos que, dada la inestabilidad de las relaciones en torno a Juan II, se podía haber considerado hasta ahora como sometido a una cierta provisionalidad.

Con todo aquel despliegue festivo, ya en el plano de la gobernación general del reino, el conde de Haro estaría haciendo exhibición de su nueva y singular posición que le señalaba como elemento decisivo en cualquier toma de decisiones tras el exilio de don Álvaro de Luna como consecuencia de las negociaciones de Tordesillas y Castronuño, en las que el conde había tenido un papel central. De este modo, con aquellas fiestas, se hacía toda una escenificación de la apertura de un nuevo tiempo político que parecía corresponderse con el de la máxima afirmación del poder y la influencia del conde de Haro.

El empeño del conde en ofrecer unas fiestas por encima de toda comparación no estaba fuera de lugar ni podía considerarse una iniciativa desmesurada. Era bien conocida en la corte la proverbial y recurrente tendencia del condestable don Álvaro de Luna a llevar a cabo esas exhibiciones festivas, sobre todo en presencia del rey. ${ }^{65}$ Era necesario que el conde fuera ahora aún más allá, haciendo perfecta emulación, si no superación, de esta imagen ceremonial del privado recién expulsado de la corte. Lógicamente, el formato no podía ser otro que el de las grandes fiestas caballerescas que respondían a modelos celebratorios estereotipados bien conocidos de toda la nobleza europea. ${ }^{66}$ Sin embargo, dentro de esos modelos preestablecidos aún había lugar para mayores exhibicionismos y dispendios, hasta llegar al extremo de reinventar la propia naturaleza como quedó patente en ese bosque prefabricado especialmente para desarrollar toda una cacería ritual.

Así, a partir de todas estas consideraciones, el itinerario festivo diseñado por el conde de Haro quedaba a la altura que exigía su posición política recién adquirida, que pronto volvería a verse puesta en entredicho ante la reacción que no se haría esperar, ya en el transcurso de 1441, por parte de don Álvaro de Luna por recuperar su antigua posición junto al rey castellano. ${ }^{67}$

64. Archivo Histórico Nacional: Sección Nobleza, Frías, caja 292, docs. 9-13.

65. Extenso repertorio de estas celebraciones organizadas con frecuencia por don Álvaro de Luna en: Crónica de don Álvaro de Luna, edición de J. de M. Carriazo, Madrid: Espasa Calpe, 1940.

66. Este modelo de fiestas caballerescas puede verse descrito en: Miguel Ángel LADERo QuesAdA: Las fiestas en la cultura medieval, Barcelona: Editorial Areté, 2004, pp. 100-108 y 129-150.

67. De esta reacción de don Álvaro de Luna y las nuevas confrontaciones a las que dio lugar puede verse extensa noticia en JuAn Abellán Pérez: Documentos de Juan II, «Colección de documentos para la Historia del Reino de Murcia, XVI, Murcia-Cádiz: Academia Alfonso X el Sabio, Servicio de publicaciones de la Universidad de Cádiz, Consejo Superior de Investigaciones Científicas, 1984, doc. 215, pp 225-230. 
Mientras que, desde el punto de vista político, el trasfondo y significado de las celebraciones resulta bien evidente a partir de las circunstancias que se acaban de apuntar, desde el punto de vista del empaque ceremonial de las fiestas realizadas, estas plantean el problema de su difícil comparación con otras similares, si se tienen en cuenta sus motivaciones y la identidad de sus principales protagonistas, dos aspectos decisivos en el análisis de cualquier espectáculo político. Con proximidad cronológica dentro del reino castellano, probablemente solo se pueda establecer parangón con las celebradas a finales de mayo de 1428 en la ciudad de Valladolid, ${ }^{68}$ acaecidas con motivo de la llegada a esta ciudad de la infanta doña Leonor de Aragón, de camino a su boda con el príncipe don Duarte, heredero de la corte portuguesa. Esta fue, en realidad, una excusa secundaria con relación a los verdaderos motivos de aquellas fiestas, más relacionados con unas tensiones crecientes entre los personajes actuantes principales que ahora se encubrían a duras penas bajo la apariencia festiva y pacífica de la cortesía caballeresca. En cualquier caso, en cuanto a pretensiones de espectacularidad, bien puedan considerarse las más próximas a las de Briviesca, resultando, de hecho, superiores en su ejecución concreta.

Junto con la coincidencia de muchas de las prácticas festivas propias de las grandes celebraciones cortesanas, quizá la similitud más relevante fuera, entre otros rasgos comparables, la gran atención dedicada a la construcción de enormes escenografías ficticias, lo que justifica que para las de Valladolid se hiciera un desembolso de no menos de 12.000 florines, una cifra fabulosa, mucho más si se tiene en cuenta que esta cantidad se refiere tan solo a lo gastado por el infante don Enrique en los actos y regalos llevados a cabo en un solo día. Pero, por otro lado, se alejan ambos acontecimientos en lo que se refiere a su muy distinta duración, los cuatro días de Briviesca frente a unas fiestas que, iniciadas el 18 de mayo, llegaron hasta «bien entrada la primera decena de junio», ${ }^{69}$ lo que, de nuevo, evidencia la superioridad de estas en cuanto a su desarrollo.

Sin embargo, más allá de la dimensión festiva y escenográfica, hay algo muy relevante que dificulta el valor de la comparación. En las de Valladolid se dieron cita dos soberanos, el rey de Navarra y el rey de Castilla, a la vez

68. Estas fiestas, descritas en la misma crónica, han sido recientemente aludidas en Miguel ÁNGEL Zalama y Jesús F. Pascual: Testamento y codicilos de Juan II de Aragón, y última voluntad de Fernando I: política y artes, Zaragoza, Institución Fernando el Católico, 2017, pp. 17-18. Ya hay algunas páginas dedicadas a estos acontecimientos festivos en Eloy Benito Ruano: Los infantes de Aragón, Madrid: Escuela de Estudios Medievales, 1952, pp. 46-49; sin embargo, los trabajos monográficos más detallados sobre estos acontecimientos pueden encontrarse en TÉ́fILO F. RUIZ: «Festivités, couleurs et symboles du pouvoir en Castille au XVe siècle. Les célébrations de mai 1428». Annales. Economies. Sociétés. Civilisations, 3, 1991, pp. 521-546 y Teófilo F. Ruiz: «Fiestas, torneos y símbolos de realeza en la Castilla del siglo XV. Las fiestas de Valladolid de 1428», en AdELINE RUCQUOI (coor.). Realidad e imagen del poder. España a fines de la Edad Media, Valladolid: Ámbito, 1988, pp. 249-265.

69. Benito Ruano, p. 46. 
que se hizo presente uno de los Trastámara más poderoso del momento, el infante don Enrique de Aragón, junto a su rival más odioso, el gran privado Álvaro de Luna, recientemente retornado a la corte tras su exilio forzoso, y todo ello en un momento político particularmente relevante para las tres monarquías que se hacían presentes, la castellana, la aragonesa y la navarra y bajo unas condiciones de evidente tensión política que implicaba directamente a todos los protagonistas citados. En cierta medida, tal como ha sido señalado por alguno de los estudiosos de este acontecimiento, aquellos grandes espectáculos vallisoletanos fueron la expresión de una especie de torneo caballeresco entre los cuatro grandes personajes políticos presentes en el escenario de las celebraciones, empeñado cada uno en protagonizar un espectáculo superior para mayor gloria y sublimación propia. ${ }^{70}$

Situación bien distinta es la que nos encontramos para los acontecimientos de Briviesca, comparables en muchos aspectos, en cuanto a boato y empaque ceremonial, aunque a menor escala, pero bien distintos en cuanto que ningún soberano se hacía presente, lo que restaba justificación en la lógica de la práctica ceremonial castellana. De hecho, quien con más detalle ha estudiado estas fiestas vallisoletanas ${ }^{71}$ pone en valor su relevancia bajo clave de expresión de los símbolos de realeza que se hicieron presentes durante su desarrollo, lo que resulta del todo punto inaplicable al caso de las de Briviesca, enteramente sometidas a la iniciativa de un conde que se mostraba como único protagonista político principal de las mismas en completa ausencia durante ellas de algún rival político que se le pudiera oponer.

El cronista que relata ambos acontecimientos los describió con notable detalle, lo que nos invita a pensar en el motivo que le llevó a calificar de forma tan superlativa como «las mayores fiestas que en España se vieron» a los acontecimientos de Briviesca, a pesar de ser bien conocidas por él las celebradas en Valladolid que describe en la misma crónica. ${ }^{72}$ En este sentido, bien pudo acaso encontrar motivación para expresarse de este modo en la desmesura festiva de unas celebraciones imposibles de imaginar en ausencia de unos soberanos que, en cambio, sí se hicieron presentes en las fiestas vallisoletanas doce años antes y que parecían por ello más justificadas. Era, probablemente, la desproporción entre valor político cuestionable y espectacularidad rotunda y desmesurada lo que, a los ojos del cronista, convirtió a los acontecimientos de Briviesca en un hecho excepcional y mayúsculo, digno, a su parecer, de los términos llamativos con los que quiso atraer la atención del lector sobre el mismo.

70. «Compitieron en agudeza de imaginación y en derroche de elementos fantásticos y pecuniarios para alegrar a los concurrentes». BENITO RUANO, p. 47.

71. RuIZ: «Fiestas...», p. 249.

72. PÉREZ de GuZMÁN, p. 566. 


\section{BIBLIOGRAFÍA}

Abellán Pérez, Juan: Documentos de Juan II, «Colección de documentos para la Historia del Reino de Murcia, XVI, Murcia-Cádiz: Academia Alfonso X el Sabio, Servicio de publicaciones de la Universidad de Cádiz, Consejo Superior de Investigaciones Científicas, 1984.

Allard, Jeanne: «L'etiquette de table à la cour de Castille au Bas Moyen Age», Temas Medievales, 3, 1993, p. 5-15.

-: «La naissance de l'etiquette: les règles de la vie à la cour de Castille à la fin du MoyenAge», en Nilda Guglielmi y Adeline Rucquoi (eds.), El Discurso político en la Edad Media, Buenos Aires: Consejo Nacional de Investigaciones Científicas y Técnicas, 1995, pp. 11-28.

ANDRÉS DíAz, RosAnA DE: «Las entradas reales castellanas en los siglos XIV y XV, según las crónicas de la época», En la España Medieval, 4, 1984, pp. 47-62.

Arsuaga Laborde, Diego: Pedro Fernández Velasco, primer conde de Haro: un estudio de la figura de un ricohombre en la Castilla del cuatrocientos, Madrid: Universidad Nacional de Educación a Distancia, 2015, http://e-spacio.uned.es/fez/view/tesisuned:GeoHisDarsuaga.

AzCONA, TARSICIO DE: «Algunos documentos esenciales sobre Blanca de Navarra, esposa de Enrique IV de Castilla», Príncipe e Viana, 78, 2017, pp. 15-35.

Benito, Ruano: Los infantes de Aragón, Madrid, Escuela de Estudios Medievales, 1952.

Cantera Burgos, Francisco: Alvar García de Santa María, Historia de la judería de Burgos y de sus conversos más egregios, Madrid: Instituto Arias Montano, 1952.

Cañas Gálvez, Francisco de Paula: Itinerario de la corte de Juan II (1418-1454), Madrid: Dykinson, 2007.

Carrasco Manchado, Ana Isabel: «La ceremonia de entrada real: ¿un modelo castellano?», en Manuel González Jiménez e Isabel Montes Romero-Camacho, La Península Ibérica entre el Mediterráneo y El Atlántico: siglos XIII-XV, Cádiz: Sociedad Española de Estudios Medievales, 2006, pp. 651-656.

-: «Léxico político en el Seguro de Tordesillas: conflicto, pactos y autoridad», en François Foronda y Ana Isabel Carrasco Manchado (dirs.): Du contrat d'alliance au contrat politique. Cultures et sociétés politiques dans la péninsule Ibérique à la fin du Moyen Age, Toulouse: Université de Toulouse, 2007, pp. 85-137.

Contreras Martín, Antonio M.: «Comida y cortesía: los rituales alimenticios en la sociedad caballeresca de los siglos XIV y XV», en Actes Ier Col.loqui d'Història de l'Alimentació a la Corona d'Aragó, Lérida: Institut d'Estudis Ilerdencs, 1995, vol. 2, pp. 711-727.

Coronado Schwindt, Gisela: «Las entradas reales en el reino de Castilla hacia el final de la Edad Media; el universo sonoro del poder», Mirabilia. Revista Electrónica de Historia Antigua y Medieval, 29, 2019.

Crónica de don Álvaro de Luna, edición de J. de M. Carriazo, Madrid: Espasa Calpe, 1940.

Crónica del Halconero, edición de J. M. Carriazo, Madrid: Espasa Calpe, 1946.

Fernández Gallardo, Luis: Alonso de Cartagena. Una biografía politica en la Castilla del siglo XV, Junta de Castilla y León, Valladolid: Junta de Castilla y León, 2002.

Franco Silva, Alfonso: «La formación del patrimonio de la Casa de Velasco (siglo XIII al XV)», Boletín de la Real Academia de la Historia, CCVI, 2009, pp. 231-254.

GARCía LuJÁn, JosÉ ANTONIO: «Una minoría urbana en el estado nobiliario de los Velasco: los judíos a través de las ordenanzas del primer conde de Haro (1431-1476)», en Tolède et l'expansion urbaine en Espagne (1450-1460), Madrid: Casa de Velázquez, 1991, pp. 249-271.

Gómez Redondo, Fernando: «Elocución y diplomacia: rivalidades culturales en Tordesillas», en François Foronda y Ana Isabel Carrasco Manchado (dirs.): $D u$ 
contrat d'alliance au contrat politique. Cultures et sociétés politiques dans la péninsule Ibérique à la fin du Moyen Age, Toulouse: Université de Toulouse, 2007, pp. 49-64.

-: Historia de la prosa medieval castellana, III, Madrid: Cátedra, 2002.

González Crespo, Esther: Elevación de un linaje nobiliario castellano en la Baja Edad Media: los Velasco, Madrid: Universidad Complutense de Madrid, 1981.

Ladero Quesada, Miguel Ángel: Las fiestas en la cultura medieval, Barcelona: Editorial Areté, 2004.

Lawrance, Jeremy N. H.: «Nueva luz sobre la biblioteca del conde de Haro: inventario de 1455», El Crotalón, 1984, pp. 1073-1111.

Marino, Nancy F.: El Seguro de Tordesillas del conde de Haro don Pedro Fernández de Velasco, Valladolid: Secretariado de Publicaciones de la Universidad de Valladolid, 1992.

Martínez AÑíbarro y Rives, Manuel: «Fernández de Velasco (Pedro), el Buen Conde de Haro» en Intento de un diccionario biográfico y bibliográfico de autores de la provincia de Burgos, Valladolid: Junta de Castilla y León, 1993, pp. 167-190.

Martínez Díez, Gonzalo: «El linaje de los Velasco», Boletín de la Institución Fernán González, 238, 2009, pp. 107-154.

Memorias de don Enrique IV de Castilla, II, Madrid: Real Academia de la Historia, 18351913.

Moreno Ollero, Antonio: «El señorío de Villalpando: de Arnao de Solier al Conde de Haro», Primer Congreso de Historia de Zamora, III, Zamora: Diputación Provincial de Zamora, 1991, pp. 397-410.

NARbona VizCAíno, RAFAel: «Las entradas reales en Valencia entre la Edad Media y la Edad Moderna. Siglos XIV-XVII», en Memorias de la ciudad. Ceremonias, creencias y costumbres en la historia de Valencia, Valencia: Ayuntamiento de Valencia, 2003, pp. 85-100.

Nieto Soria, José Manuel: «El auto de Ávila de 1420», en María Isabel Del Val Valdivieso y Pascual Martínez Sopena (dirs.): Castilla y el mundo feudal. Homenaje al profesor Julio Valdeón, II, Valladolid: Junta de Castilla y León, 2009, pp. 679-690.

-: Las ceremonias de la realeza. Propaganda y legitimación en la Castilla Trastámara, Madrid: Editorial Nerea, 1993.

Ortega Martínez, Ana Isabel y Ibarra Álvarez, José Luis: «La villa de Briviesca en la Baja Edad Media: datos y reflexiones para su estudio», Boletín de la Institución Fernán González , 217, 1998, p. 321-352.

Palencia, Alfonso de: Gesta Hispaniensia ex annalibus suorum dierum collecta, edición de B. Tate y J. Lawrance, Madrid: Real Academia de la Historia, 1998.

Paulino Montero, Elena: El patrocinio arquitectónico de los Velasco (1313-1512): construcción y un contexto de un linaje en la Corona de Castilla, Madrid: Universidad Complutense de Madrid, 2015.

Paz y Meliá, Antonio: «Biblioteca fundada por el Conde de Haro en 1455», Revista de Archivos, Bibliotecas y Museos, 1897, pp. 18-24, 60-66, 156-163, 255-262, 452-462; 4, 1900 , pp. 535-541, 662-667; 6, 1902, pp. 198-206, 372-382; 7, 1902, pp. 51-55; 19, 1908, pp. 124136; 20, 1909, pp. 277-289.

Pelaz Flores, Diana: «El don: Pulso entre el significado del gasto y la simbología del poder en la entrada de la familia real a Burgos en 1441», en Alexandra Beauchamp, Antoni Furió Diego, Germán Gamero Igea y María Narbona Cárceles (eds.), Acoger, abastecer y financiar la corte. Las relaciones entre las cortes ibéricas y las sociedades urbanas a finales de la Edad Media, Valencia: Publicaciones de la Universidad de Valencia, 2019, pp. 347-360.

Pérez de Guzmán, Fernán: «Crónica de Juan II», Crónicas de los Reyes de Castilla, II, Madrid: Atlas, 1953.

Pulgar, Fernando del: Claros varones de Castilla, edición de J. Domínguez Bordona, Madrid: Espasa Calpe, 1969. 
Rábade Obradó, María del Pilar: «Confederaciones, seguros y pleitos homenajes: el contexto documental del Seguro de Tordesillas», en François Foronda y Ana Isabel Carrasco Manchado (dirs.): Du contrat d'alliance au contrat politique. Cultures et sociétés politiques dans la péninsule Ibérique à la fin du Moyen Age, Toulouse: Université de Toulouse, 2007, pp. 65-84.

Raufast Chico, Miquel: «Ceremonia y conflicto: entradas reales en Barcelona en el contexto de la Guerra Civil catalana (1460-1473)», Anuario de estudios medievales, 38, 2008, p. 1037-1085.

—: «La entrada real de Martín el Joven, rey de Sicilia en Barcelona (1405): solemnidad, economía y conflicto», Acta historica et archaeologica mediaevalia, 27/28, 2006/07, p. 89-120.

Ruiz, Teófilo F.: «Festivités, couleurs et symboles du pouvoir en Castille au XVe siècle. Les célébrations de mai 1428». Annales. Economies. Sociétés. Civilisations, 3, 1991, pp. 521546.

—: «Fiestas, torneos y símbolos de realeza en la Castilla del siglo XV. Las fiestas de Valladolid de 1428», en Adeline RuCQuoi (coor.). Realidad e imagen del poder. España a fines de la Edad Media, Valladolid, Ámbito, 1988, pp. 249-265.

Romagnoli, DANIELA: «'Mind tour manner': etiquette at the table», en JEAN Louis FLANDRIN y Massimo Montanari (eds.), Food. A culinary history from antiquity to the present, Nueva York: Stein and Day, 1998, pp. 328-338.

SAlvador Miguel, NicASiO: «El divorcio del príncipe don Enrique de Castilla y doña Blanca de Navarra (1453)», La literatura en la época de los Reyes Católicos, Madrid: Editorial Iberoamericana, 2008, pp. 249-274.

VArios Autores: El marqués de Santillana, 1398-1458. Los albores de la España moderna, 4 vols., Hondarribia: Editorial Nerea, 2002.

Visceglia, Maria Antonietta: Riti di corte e simboli della regalità. I regni d'Europa e del mediterraneo dal Medioevo all'età moderna, Roma: Salerno Editrice, 2009.

YARZA LUACES, JOAQUín: La nobleza ante el rey. Los grandes linajes castellanos y el arte en el siglo XV, Madrid: Ediciones El Viso y Fundación Iberdrola, 2003.

-: «Imagen del noble en el siglo XV en la Corona de Castilla: Los Velasco anteriores al primer Condestable», en Marisa Costa (coor.): Propaganda y poder, Congresso Peninsular de História da Arte, Lisboa: Ediciones Colibrí, 2001, pp. 131-149.

Yepes López, José y Sagredo Fernández, Félix: «Las Arcas de Limosna del Conde de Haro y las Instituciones de préstamo benéfico (siglos XV-XVI)», en A pobreza e a assisténcia aos pobres na península ibérica durante a Idade Média , II, Lisboa: Instituto de Alta Cultura. Centro de Estudios Históricos Anexo à Faculdade de Letras da Universidade de Lisboa, 1975, pp. 547-574.

Zalama, Miguel Ángel y Pascual, Jesús F.: Testamento y codicilos de Juan II de Aragón, y última voluntad de Fernando I: política y artes, Zaragoza, Institución Fernando el Católico, 2017. 